\title{
Evaluasi Website Perguruan Tinggi Menggunakan Metode Usability Testing
}

\author{
Agus Setiawan $^{1 *}$, R. Arri Widyanto ${ }^{2}$ \\ ${ }^{1,2}$ Program Studi Teknik Informatika, Fakultas Teknik, Universitas Muhammadiyah Magelang \\ ${ }^{1,2} \mathrm{Jl}$. Mayjend Bambang Soegeng km 5 Mertoyudan, Magelang, 56172, Indonesia \\ email: ${ }^{1 *}$ setiawan@ummgl.ac.id, ${ }^{2}$ arri_w@ummgl.ac.id \\ Received: 27 April 2018; Revised: 1 Oktober 2018; Accepted: 17 Oktober 2018 \\ Copyright @2018, Politeknik Harapan Bersama, Tegal
}

\begin{abstract}
Utilization of information technology on this day has become an unavoidable need. Utilization of website as a promotion event of an institution or organisation still not optimal because not follow usability aspect/usability. The interface of the university website should be a reflection of the university itself. Evaluation of the interface of the university website should be done to find out how high the usability level of university website development. Using usability testing method is expected to be able to measure the usability level of the university website to maximise the promotion of Higher Education in cyberspace. Methods to measure using quantitative methods by spreading questionnaires to the respondents. Research indicators use usability indicators that include Learnability, Memorability, Efficiency, Errors, and Satisfaction. The questionnaire tested its validity and reliability before use. Questionnaires are distributed freely to internal and external residents of Higher Education. 95 Respondents filled out questionnaires that had been scattered. Assessment method using a Likert scale with four levels, namely: Strongly Agree; Agree; Disagree; Strongly Disagree. The results of this study concluded that the university website has a final value of $\mathbf{2 . 7 7}$ where this value is still in the excellent category. The lowest value of the five aspects of usability is in the Errors aspect of obtaining a value of 2.65 .
\end{abstract}

Abstrak - Pemanfaatan teknologi informasi pada hari ini sudah menjadi kebutuhan yang tidak bisa dihindarkan. Pemanfaatan website sebagai ajang promosi sebuah lembaga atau organisasi masih belum optimal karena belum mengikuti aspek kebergunaan / usability. Tampilan antarmuka website Perguruan Tinggi perlu menjadi cerminan dari Perguruan Tinggi itu sendiri. Evaluasi terhadap tampilan antarmuka website Perguruan Tinggi perlu dilakukan untuk mengetahui seberapa tinggi level usability dari pengembangan website Perguruan Tinggi. Menggunakan metode usability testing ini diharapkan mampu mengukur level usability dari website Perguruan Tinggi untuk memaksimalkan ajang promosi Perguruan Tinggi di dunia maya. Metode untuk mengukur menggunakan metode kuantitatif dengan menyebar kuesioner kepada para responden. Indikator penelitian memakai indikator usability yang meliputi Learnability, Memorability, Efficiency, Errors, dan Satisfaction. Sebelum digunakan kuesioner diuji validasi dan reliabilitasnya. Kuesioner disebar bebas kepada warga internal dan eksternal Perguruan Tinggi. 95 Responden mengisi kuesioner yang telah disebar dengan skala likert dengan empat jenjang, yaitu: Sangat Setuju; Setuju; Tidak Setuju; Sangat Tidak Setuju. Hasil

*) Corresponding author: (Agus Setiawan)

Email: setiawan@ummgl.ac.id penelitian ini menyimpulkan bahwa website Perguruan Tinggi mempunyai nilai akhir 2.77 di mana nilai ini masih pada kategori baik. Nilai terendah dari kelima aspek usability ada pada aspek Errors yaitu mendapatkan nilai 2.65.

Kata Kunci - human-computer interaction, usability, user interface, user experience

\section{PENDAHULUAN}

Pemanfaatan teknologi informasi pada hari ini sudah menjadi kebutuhan yang tidak bisa dihindarkan [1]-[3]. Menurut data APJII pengguna internet Indonesia pada bulan Januari tahun 2016 sudah mencapai 88 juta [4], [5] Tentunya penggunaan internet ini akan setiap waktu mengalami peningkatan, karena pemerintah dan swasta terus memberikan fasiilitas yang semakin lama semakin menjangkau daerah baru daerah pelosok [6], [7]. Dalam menggunakan internet perlu menemukan sumber yang sah dan terpercaya sehingga perlu memahami etika berinternet [1], [8].

Website merupakan situs berbasis teknologi web yang memungkinkan pengguna mendapatkan informasi dari berselancar (browsing). Pengguna komputer yang terhubung dengan internet dapat berselancar untuk mendapatkan informasi dengan mengunjungi website - website yang sudah tersebar di dunia maya. Universitas Muhammadiyah Magelang (UMMgl) mempunyai website sebagai wajah di dunia maya dengan alamat situs http://ummgl.ac.id, melalui website dengan alamat tersebut dapat digunakan untuk mendapatkan informasi tentang UMMgl. Namun demikian, pemanfaatan website sebagai ajang promosi belum mendapatkan perhatian yang lebih di dunia pendidikan. Website masih dianggap sebagai fasilitas pendukung yang bisa dikatakan asal ada. Banyak website yang tidak dikelola dan tidak diperbaharui sesuai dengan perkembangan jaman dan menyesuaikan target dari pengguna yang menggunakan website itu nantinya.

Salah satu solusi penyelesaian masalah untuk memberikan tampilan dari antarmuka yang memuaskan untuk para pengguna yang mengakses website dari UMMgl adalah mengacu pada indikator dari aspek usability. Pemanfaatan website sebagai ajang promosi sebuah lembaga perlu diukur kebergunaannya untuk mengetahui seberapa pengguna puas dengan tata letak dari tampilan antarmuka website tersebut. Masih berbicara tentang tata letak belum lagi berbicara 
tentang isi dari sebuah website sebagai ajang promosi di dunia maya. UMMgl yang mempunyai website dengan alamat situs http://ummgl.ac.id perlu di ukur untuk meningkatkan kepuasan pada pengunjung website-nya.

Tujuan dari penelitian ini adalah untuk mengukur antarmuka website UMMgl untuk memberikan rekomendasi perbaikan secara detail mengikuti aspek usability yang nantinya dapat memuaskan para pengunjung website sehingga mampu meningkatkan jumlah pengunjung website $\mathrm{UMMgl}$ sebagai media promosi.

\section{PENELITIAN YANG TERKAIT}

Menurut Nan $\mathrm{Yu}$, Website dijaman sekarang ini perlu dikembangkan dengan desain untuk tampilan pada perangkat mobile atau pada layar yang terbatas, karena dengan portabilitasnya sekarang banyak orang mengakses website melalui perangkat mobile-nya [9]. Menurut (MZ, 2016) dalam artikelnya juga mengevaluasi website Universitas Janabadra yang mempunyai kesimpulan nilai terendah ada pada faktor memorability, walaupun masih kategori cukup namun masih perlu pengembangan untuk meningkatnya agar pengunjung lebih mudah menyerap informasi yang disajikan [10]. Penelitian serupa juga dilakukan oleh (Sulasih \& Tarmuji, 2015) yang menganalisa website Universitas Ahmad Dahlan menggunakan instrumen dengan model jawaban "IYA" dan "TIDAK" memberikan kesimpulan bahwa website UAD masih perlu pengembangan, namun belum detail rekomendasi dari perbaikan yang perlu dilakukan [11]. Berkaitan dengan pengujian lain yang memanfaatkan usability testing juga sesuai dengan ISO 9126 yang mempunyai 4 faktor atau aspek yang diujikan, adalah usability, functionality, portability, dan efficiency [12].

Penelitian terdahulu yang dilakukan oleh Venkatesh dkk ini juga menerapkan usability testing. Namun ini dilakukan untuk menguji website lembaga amal dari Obamacare. Venkatesh mengembangkan instrument penelitian ini menjadi 16 dimensi dan jumlah responden sejumlah 374 [13]. Venkatesh memberikan rekomendasi pada hasil penelitiannya untuk fokus pada website kesehatan milik pemerintah.

Ekmel cetin dalam penelitiannya yang berjudul A Study on an Educational Website's Usability melakukan penelitian yang fokus pada struktrur interaksi pada website Morpa Campus. Penelitian dilakukan dengan memberikan beberapa kegiatan dari yang sangat mudah sampai yang sulit. Tiga hal utama yang menjadi fokus adalah Efficiency, Ease of Use, dan Satisfaction [14]. Rekomendasi penelitian yang sudah dilakukan Ekmel adalah menghapus beberapa tombol dan mengganti beberapa symbol tombol agar mudah dipahami dan lebih mudah digunakan [14].

Nan Yu dan Jun Kong pada penelitiannya fokus pada pengujian pengalaman pengguna menggunakan web-browser dengan layar terbatas atau kecil pada smartphone. Penelitian ini memberikan rekomendasi dasar pada segenap interface designer bagaimana membangun antarmuka pada layar yang terbatas [9]. Nan $\mathrm{Yu}$ berpendapat bahwa tampilan yang melebar dapat memberikan kecepatan pembacaan dan mudah digunakan pada web untuk kategori berita. Kelemahan dari penelitian ini adalah rentang umur dari penelitian ini antara 18-30 tahun.
Penelitian terkait dengan evaluasi antarmuka website yang menghasilkan rekomendasi perbaikan secara detail masih belum banyak dilakukan. Rekomendasi perbaikan antarmuka website dilakukan berdasarkan analisis nilai terendah dari masing - masing variabel penelitian. Sehingga nilai yang terendah dapat diketahui untuk dilakukan perbaikan melalui rekomendasi berdasarkan evaluasi tersebut.

\section{METODE PENELITIAN}

Metode penelitian yang digunakan oleh peneliti menggunakan metode survei dengan memakai kuesioner yang disebar kepada responden, responden dalam penelitian ini adalah civitas akademika UMMgl sebagai pengguna website dan para pihak eksternal yang bersedia untuk memberikan penilaian menggunakan instrumen yang telah disediakan. Kuesioner yang disusun berisi daftar pertanyaan berdasarkan aspek usability. Tahapan penelitian dapat digambarkan sesuai dengan Gbr 1.

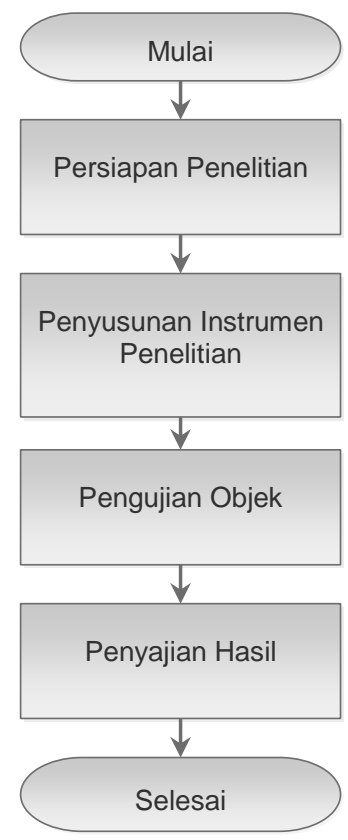

Gbr. 1 Tahapan Penelitian

\section{A. Persiapan Penelitian}

Pada tahapan ini peneliti mempersiapkan segala hal yang akan dilakukan dalam penelitian. Kegiatan pendukung itu adalah penulis melakukan studi literatur untuk mendapatkan bahan kajian yang sesuai dengan topik penelitian. Penulis mengkaji beberapa model penilaian website menggunakan metode usability testing. Penulis juga melakukan telaah teknologi yang mutakhir untuk mendukung penelitian yang dilakukan. Selain itu penulis mengkaji sistem yang sedang berjalan untuk mengobservasi objek penelitian agar tidak luput dari penilaian.

\section{B. Penyusunan Instrumen Penelitian}

Instrumen penelitian berupa angket yang disusun menurut indikator dari aspek usablitity yang meliputi hal - hal sebagai berikut [4]:

- Kemudahan untuk digunakan,

- Model Interaksi website yang jelas dan mudah 
- Navigasi yang mudah,

- Tampilan atraktif,

- Tampilan sesuai jenis website,

- Ada tambahan pengetahuan dari informasi website,

- Penyusunan tata letak informasi tepat,

- Alamat website mudah dicari.

Penyusunan instrumen menjadi hal yang penting karena instrumen ini akan digunakan nantinya untuk mengukur objek penelitian. Sesuai dengan fungsinya sebagai alat ukur maka penulis harus memastikan alat ukur tersebut valid dan reliabel. Pada Tabel I, terlihat indikator - indikator sesuai dengan aspek usability.

TABEL I

JUMLAH BUTIR KUESIONER

\begin{tabular}{|c|l|c|l|}
\hline No. & \multicolumn{1}{|c|}{ Indikator } & $\begin{array}{c}\text { Butir } \\
\text { Pertanyaan }\end{array}$ & $\begin{array}{c}\text { Nomor } \\
\text { Butir }\end{array}$ \\
\hline 1 & Learnability $[A]$ & 5 & $1,2,3,4,5$ \\
\hline 2 & Memorability $[B]$ & 3 & $6,7,8$ \\
\hline 3 & Efficiency $[C]$ & 3 & $9,10,11$ \\
\hline 4 & Errors $[D]$ & 3 & $12,13,14$ \\
\hline 5 & Satisfaction $[E]$ & 4 & $15,16,17,18$ \\
\hline \multicolumn{2}{|c|}{ Total } & 18 & \\
\hline
\end{tabular}

TABEL II

SEBARAN KUESIONER PADA TIAP ASPEK USABILITY

\begin{tabular}{|c|c|c|c|}
\hline No & Aspek & Indikator & Butir \\
\hline \multirow{5}{*}{1} & \multirow{5}{*}{$\begin{array}{l}\text { Learnability } \\
{[A]}\end{array}$} & Website mudah dipelajari & 1 \\
\hline & & Informasi spesifik & 2 \\
\hline & & $\begin{array}{l}\text { Penyajian konten mudah } \\
\text { dipahami }\end{array}$ & 3 \\
\hline & & Alur navigasi mudah & 4 \\
\hline & & $\begin{array}{l}\text { Tidak membutuhkan } \\
\text { instruksi khusus }\end{array}$ & 5 \\
\hline \multirow[b]{2}{*}{2} & \multirow[b]{2}{*}{$\begin{array}{l}\text { Memorability } \\
{[B]}\end{array}$} & Website mudah diingat & 6 \\
\hline & & $\begin{array}{lll}\text { Alur navigasi } & \text { mudah } \\
\text { diingat }\end{array}$ & 7,8 \\
\hline \multirow[b]{2}{*}{3} & \multirow[b]{2}{*}{ Efficiency $[C]$} & Kecepatan akses menu & 9 \\
\hline & & $\begin{array}{l}\text { Kecepatan mendapatkan } \\
\text { informasi }\end{array}$ & 10,11 \\
\hline \multirow{2}{*}{4} & \multirow{2}{*}{ Errors $[D]$} & Kesalahan website & 12 \\
\hline & & Keaktifan menu & 13,14 \\
\hline \multirow{4}{*}{5} & \multirow{4}{*}{ Satisfaction [E] } & $\begin{array}{l}\text { Kenyamanan tampilan } \\
\text { website }\end{array}$ & 15 \\
\hline & & $\begin{array}{l}\text { Kenyamanan penjelajahan } \\
\text { website }\end{array}$ & 16 \\
\hline & & $\begin{array}{l}\text { Keluwesan tata letak dan } \\
\text { konten }\end{array}$ & 17 \\
\hline & & $\begin{array}{l}\text { Kesesuaian dengan judul } \\
\text { dan konten }\end{array}$ & 18 \\
\hline
\end{tabular}

Menurut [15], instrumen yang valid adalah apabila instrumen dapat mengukur apa yang seharusnya diukur. Instrumen dapat dikatakan valid jika alat ukur yang digunakan untuk mendapatkan data itu valid. Instrumen yang reliabel adalah instumen yang saat dipergunakan berulangkali untuk mengukur obyek yang sama, akan menghasilkan data yang konsisten dan stabil. Indeks validitas instrumen yang dipakai dalam penelitian ini dapat dicermati dari nilai $r$ pada kolom corrected item-total correlation, saat nilai $r$ hasilnya positif dan lebih besar dari $r$ tabel, maka butir/item itu valid [16]. Nilai $r$ hasil pada kolom corrected-item-totalcorrelation akan lebih teliti jika kita dibandingkan nilai koefisien korelasi momen produk dengan Pearson. Berdasrakan kaitan besarannya angka korelasi ini, maka item dari variabel yang dipakai dikatakan valid jika memiliki koefisien minimal 0.3 [16]. Ketentuan validitas ini adalah syarat minimum, seperti yang jelaskan oleh ahli yaitu Cronbach (1970) yang dikutip [17]. Jika angka korelasi hasil perhitungan lebih besar dari angka kritis, maka butir/item pertanyaan tersebut valid dan signifikan. Sebaliknya, jika angka korelasi hasil perhitungan lebih kecil dari angka kritis tabel korelasi, maka item pertanyaan tersebut dapat dikatakan tidak signifikan dan harus diperbaiki bahkan digugurkan [17].

\section{Pengujian Objek Penelitian}

Pengujian objek penelitian dilakukan menggunakan kuesioner. Kuesioner disebar umum kepada para pengakses website UMMgl. Sebelum melakukan pengisian terhadap kuesioner, para responden diminta untuk mengakses website UMMgl pada laman http://ummgl.ac.id/ terlebih dahulu, sebaran kuesioner seperti pada Tabel II.

\section{Penyajian Hasil}

Hasil pengukuran terhadap website $\mathrm{UMMgl}$ ditampilkan berdasarkan masing-masing indikator aspek dari usability. Penulis akan merata-rata hasil pengukuran namun tetap akan melihat masing-masing nilai dari indikator penyusun usability.

\section{HASIL DAN PEMBAHASAN}

Hasil penyebaran kuesioner didapatkan 95 responden yang telah mengisi dan menilai website UMMgl. Hasil pengisian ini kemudian dilakukan pengujian validasi dan reliabilitas menggunakan perangkat lunak SPSS. Berdasarkan uji validasi menggunakan SPSS dengan melihat R-Tabel dengan jumlah responden 95 orang, maka didapatkan R-Tabel 0.236. Dengan melihat hasil uji validasi ini R-Hitung mempunyai nilai lebih besar dari R-Tabel, sehingga dinyatakan valid, dapat dilihat pada Tabel III.

Sedangkan uji Reliabilitas menggunakan SPSS juga dilakukan agar dipastikan hasil pengukuran ini dipastikan reliabel. Hasil pengujian dapat dilihat pada Tabel IV. Sesuai dengan hasil yang diperoleh yaitu 0.948 maka ini termasuk kategori "sangat dapat dipercaya". Sehingga $100 \%$ hasil pengukuran dari 95 responden dinyatakan valid dan reliabel.

Setelah semua hasil pengukuran diuji validasi dan reliabilitasnya, maka penulis melanjutkan dengan menghitung nilai usability website UMMgl. Berdasarkan Tabel VI diperoleh nilai masing - masing indikator penyusun pada aspek usability. Dapat dilihat bahwa hasil pengukuran usability semua item pernyataan dari item 1 sampai dengan item 18 mendapatkan nilai diatas 2. Sehingga dengan arti ini maka semua pernyataan mendapatkan nilai yang baik bahkan ada yang mendekati nilai maksimum yaitu sangat baik. Dengan mendapatkan hasil pengukuran ini maka dapat diambil sebuah kesimpulan juga untuk meningkatkan dan memperbaiki nilai yang masih minimum dan mempertahankan nilai yang sudah tinggi. Namun dari itu nilai masih dibawah 3 sehingga semua aspek usability masih perlu ditingkatkan. Perbaikan website Perguruan Tinggi dapat 
dilakukan dengan memperhatikan dengan seksama apa saja yang menjadi indikator penentu agar nilai website ini sangat baik dari aspek usability.

TABEL III

HASIL UJI VALIDASI INSTRUMEN

\begin{tabular}{|c|c|c|}
\hline Kode & R-Hitung & R-Table \\
\hline A1 & .799 & .236 \\
\hline A2 & .734 & .236 \\
\hline A3 & .803 & .236 \\
\hline A4 & .689 & .236 \\
\hline A5 & .739 & .236 \\
\hline B1 & .696 & .236 \\
\hline B2 & .712 & .236 \\
\hline B3 & .706 & .236 \\
\hline C1 & .657 & .236 \\
\hline C2 & .730 & .236 \\
\hline C3 & .764 & .236 \\
\hline D1 & .453 & .236 \\
\hline D2 & .631 & .236 \\
\hline D3 & .636 & .236 \\
\hline E1 & .674 & .236 \\
\hline E2 & .790 & .236 \\
\hline E3 & .572 & .236 \\
\hline E4 & .700 & .236 \\
\hline
\end{tabular}

TABEL IV

HASIL UJI RELIABILITAS INSTRUMEN

\begin{tabular}{|r|r|r|}
\hline $\begin{array}{c}\text { Cronbach } \\
\text { 's Alpha }\end{array}$ & $\begin{array}{c}\text { Cronbach's } \\
\text { Alpha Based on } \\
\text { Standardized } \\
\text { Items }\end{array}$ & N of Items \\
\hline .948 & .949 & 18 \\
\hline
\end{tabular}

TABEL V

SUMMARY HASIL PENGUJIAN TERHADAP 95 RESPONDEN

\begin{tabular}{|l|l|r|r|}
\hline \multicolumn{2}{|c|}{} & \multicolumn{1}{|c|}{ N } & \multicolumn{1}{c|}{$\%$} \\
\hline \multirow{3}{*}{ Cases } & Valid & 95 & 100.0 \\
\cline { 2 - 4 } & Excluded $^{\mathrm{a}}$ & 0 & .0 \\
\cline { 2 - 4 } & Total & 95 & 100.0 \\
\hline
\end{tabular}

TABEL VI

NILAI MASING-MASING INDIKATOR PADA ASPEK USABILITY

\begin{tabular}{|c|c|c|}
\hline & Rerata & $\begin{array}{c}\text { Rerata } \\
\text { /Indikator }\end{array}$ \\
\hline A1 & 2.94 & 2.83 \\
\hline A2 & 2.80 & \\
\hline A3 & 2.82 & \\
\hline A4 & 2.82 & \\
\hline A5 & 2.77 & \\
\hline B1 & 2.87 & 2.84 \\
\hline $\mathrm{B} 2$ & 2.80 & \\
\hline B3 & 2.83 & \\
\hline $\mathrm{C} 1$ & 2.75 & 2.73 \\
\hline $\mathrm{C} 2$ & 2.73 & \\
\hline C3 & 2.71 & \\
\hline D1 & 2.59 & 2.65 \\
\hline D2 & 2.62 & \\
\hline D3 & 2.74 & \\
\hline E1 & 2.77 & 2.79 \\
\hline E2 & 2.80 & \\
\hline E3 & 2.78 & \\
\hline E4 & 2.82 & \\
\hline
\end{tabular}

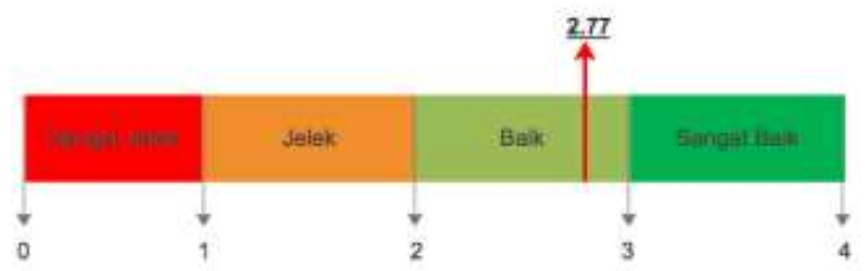

Gbr. 2 Posisi hasil Pengukuran terhadap Skala Likert

Hasil akhir dari menghitung rerata semua item pernyataan didapatkanlah nilai sebesar 2.77 yang dapat dilihat pada $\mathrm{Gbr}$ 2. Dapat dilihat sesuai dengan Gbr. 2 maka posisi website UMMgl masuk pada kategori Baik.

Penelitian lanjutan dari penelitian ini adalah nantinya akan diukur juga tingkat usability menggunakan metode Guerilla Usability Testing untuk mendapatkan evaluasi yang berbeda dan mendapatkan hasil pengukuran yang lebih detail dengan melibatkan pengguna atau responden diukur dari segi User Interface dan User Experience.

\section{KESIMPULAN}

Berdasarkan hasil pengukuran tingkat usability website UMMgl dengan nilai 2.77 dengan skala $0-4$, maka website $\mathrm{UMMgl}$ dinyatakan pada kategori website yang usable. Nilai tertinggi pengukuran ada pada Memorability dengan nilai 2.84 yang artinya adalah website mudah diingat navigasi dan tata letak untuk mendapatkan informasi. Nilai terendah ada pada Errors dengan nilai 2.65 yang mempunyai arti bahwa 
website masih banyak ditemui error pada tautan menu dan navigasi (broken link). Saran penelitian berikutnya adalah pengukuran usability yang dilengkapi dengan beberapa model penugasan atau task. Penugasan dilakukan untuk menyelesaikan beberapa tugas dari tugas yang mudah sampai yang sulit (memerlukan beberapa langkah).

\section{UCAPAN TERIMA KASIH}

Penulis mengucapkan terimakasih yang sebesar-besarnya kepada pihak LP3M Universitas Muhammadiyah Magelang yang telah memberikan kesempatan dengan hibah penelitiannya, dan Kepada para responden yang penulis tidak bisa menyebutkan satu per satu.

\section{DAFTAR PUSTAKA}

[1] A. Setiawan, "Analisis Sistem Informasi Orang Tua Wal Mahasiswa berbasis Website Studi Kasus Universitas Muhammadiyah Magelang," J. Inform. UPGRIS, vol. 2, no. 1, pp. 8-17, 2016.

[2] A. Setiawan and R. Widaryanto, "Hubungan Orang Tua Wali Mahasiswa dengan Perguruaan Tinggi dalam Sistem Informasi Orang Tua Wali Mahasiswa," in The 6th University Research Colloquium, 2017, pp. 1-6.

[3] U. Syafiqoh, S. Sunardi, and A. Yudhana, "Pengembangan Wireless Sensor Network Berbasis Internet of Things untuk Sistem Pemantauan Kualitas Air dan Tanah Pertanian," J. Inform. J. Pengemb. IT, vol. 3, no. 2, pp. 285-289, 2018.

[4] APJII, "PROFIL PENGGUNA INTERNET INDONESIA 2016," 2016. .
[5] I. Banyumurti, "Statistik Internet Indonesia 2016," 2016.

[6] Y. Paragian, "Dalam 5 tahun terakhir, jumlah pengguna internet Indonesia naik 430 persen (GRAFIK)," 2014. .

[7] A. Setiawan and R. Widaryanto, "Mobile CRM student-parent information system," IOP Conf. Ser. Mater. Sci. Eng., vol. 403, p. 12076, Oct. 2018.

[8] D. B. Napitupulu, "Evaluasi Kualitas Website Universitas XYZ Dengan Pendekata Webqual [Evaluation of XYZ University Website Quality Based on Webqual Approach]," Bul. Pos dan Telekomun., vol. 14, no. 1, p. 51, 2016.

[9] N. Yu and J. Kong, "User experience with web browsing on small screens: Experimental investigations of mobile-page interface design and homepage design for news websites," Inf. Sci. (Ny)., vol. 330, pp. 427-443, 2016.

[10] Y. MZ, "Evaluasi Penggunaan Website Universitas Janabadra Dengan Menggunakan Metode Usability Testing," Inf. Interaktif, vol. 1, no. 1, pp. 34-43, 2016.

[11] D. Sulasih and A. Tarmuji, "ANALISIS WEBSITE UNIVERSITAS AHMAD DAHLAN DENGAN METODE USABILITY TESTING,” J. Sarj. Tek. Inform., vol. 3, no. 2, 2015.

[12] A. Zulkarnais, P. Prasetyawan, and A. Sucipto, "Game Edukasi Pengenalan Cerita Rakyat Lampung Pada Platform Android," $J$. Inform. J. Pengemb. IT, vol. 3, no. 1, pp. 96-102, 2018.

[13] V. Venkatesh, H. Hoehle, and R. Aljafari, "A usability evaluation of the Obamacare website," Gov. Inf. Q., vol. 31, no. 4, 2014.

[14] E. Çetin and S. Özdemir, "A Study on an Educational Website's Usability," Procedia - Soc. Behav. Sci., vol. 83, pp. 683-688, 2013.

[15] Sugiyono, Metode Penelitian Kuantitatif, Kualitatif dan R\&D. Bandung: Alfabeta, 2009.

[16] A. Saifuddin, Reliabilitas dan Validitas (Edisi 4). Pustaka Pelajar, 2012.

[17] U. Sekaran, Metode Riset Bisnis. Salemba Empat, 2006. 